SCIREA Journal of Medicine

http://www.scirea.org/journal/PM

September 28, 2021

Volume 5, Issue 4, August 2021

\title{
SUPRAVENTRICLUAR TACHYCARDIA REVEALING A HEART MALPOSITION IN A 68-YEAR-OLD ADULT : CASE REPORT
}

MAKANI BASSAKOUAHOU Jospin Karel ${ }^{1, *}$, KOUALA LANDA Chistian Michel ${ }^{2}$, KIMBALLY-KAKY Eric Gibrel², GANKAMA Thibaut Naibe' ${ }^{1}$, IKAMA Méo Stéphane ${ }^{2}$, ELLENGA MBOLLA Bertrand Fikhaem², KIMBALLY KAKY Syzy Gisèle ${ }^{2}$

${ }^{1}$ Department of cardiology, Teaching hospital of Brazzaville, Congo

${ }^{2}$ Health Science Faculty, Marien Ngouabi University, Brazzaville, Congo

*Corresponding author :

MAKANI BASSAKOUAHOU Jospin Karel

Email : jospinmakani@gmail.com

Phone number : 00242066755707

Postal box : 32, Brazzaville, Congo

\begin{abstract}
Cardiac arrhythmias rarely complicate congenital heart disease in not operated adult. We report a case of cardiac malposition revealed by a supraventricular tachycardia. The clinical symptoms were dominated by recurrent palpitations. Attention was captivated by lack of cardiac activity in left chest part. Chest x-ray showed dextrocardia with cardiac apex and aortic arch on the right side. The electrocardiogram showed narrow QRS tachycardia
\end{abstract}


responding to sinocarotid massage. Echocardiography revealed situs inversus with atrioventricular and ventriculo-arterial concordance.

Keywords: supraventricular tachycardia, dextrocardia, situs inversus, case report

\section{Introduction}

Cardiac arrhythmias rarely complicate congenital heart disease in not operated adult [1]. Their mechanism may be the result of the impact of cardiovascular risk factors common in elderly patients [2]. However, patients with dextrocardia have high risk of cardiac arrhythmia compared to general population. Clinical expression being related to atrial fibrillation or atrial flutter [3]. The particularity of this case is the association of supraventricular tachycardia rarely reported in this context.

\section{Case report}

Mrs M.G, 68-year-old, hypertensive patient admitted to the department of cardiology at the Teaching Hospital of Brazzaville (Congo) for recurrent attacks of palpitations. She has no family history of congenital disease. Clinical examination showed that there was no heartbeat in the left chest part. Heartbeats were detected at the 5th right intercostal space. Heart sounds were regular, heart rate at 160 beats per minute without abnormal added noises. The blood pressure was 160/90 $\mathrm{mmHg}$. The rest of clinical examination was normal. The frontal chest $\mathrm{x}-$ ray showed dextrocardia, cardiomegaly (cardiothoracic ratio $=63 \%$ ), an aortic arch on the right side [Figure 1]. Electrocardiogram performed in conventional position noted regular tachycardia with narrow QRS without $\mathrm{P}$ waves. Right QRS axis, absence of $\mathrm{R}$ wave in derivations I, AVL and from V2 to V4; small $\mathrm{r}$ and large $\mathrm{S}$ waves in V1[Figure 2]. The symmetrical inversion of electrodes let appear normal progression of $\mathrm{R}$ wave. Sinocarotid massage produced a significant and transient reduction of heart rate. Echocardiography showed situs inversus, atrioventricular and ventriculo-arterial concordance, aortic arch on the right making a mirrored heart [Figure 3]. In addition atrial dilatation (left atrial $=24 \mathrm{~cm}^{2}$, right atrial $=24 \mathrm{~cm}^{2}$ ) and hyperdynamic ejection fraction of left ventricle $(\mathrm{EF}=84 \%)$. Electrophysiology study was not performed by lack of laboratory. The diagnosis of supraventricular tachycardia and dextrocardia with situs inversus was retained. The patient 
was treated with Verapamil inducing rapid return to sinus rhythm as confirmed by long-term electrocardiogram [Figure 4].

\section{Discussion}

Congenital heart disease is often found in childhood. Some of them may go unnoticed and discovered accidentally or through complications, including heart rhythm disorder [4]. However, dextrocardia can remain asymptomatic in the absence of others associated cardiac abnormalities [5]. Patients with dextrocardia have high risk of atrial fibrillation or atrial flutter [3] supraventricular tachycardia observed in our patient seems to be induce by atrial dilation, this last constituting an arrhythmogenic substrate and, itself being the atrial impact of barometric overload of high blood pressure or other cardiovascular risk farctors as described by Barre in France [1]. However the unavailability of electrophysiology laboratory did not allow an exact mapping of the supraventricular arrythmia.

\section{Conclusion}

Cardiac malposition in adult is a rare condition and the occurrence of supraventricular tachycardia exceptional. Mechanism of this last stay unclear, probably caused by arrhythmogenic substrate resulting of atrial modifications due to common cardiovascular risk factors.

\section{Figure legends :}

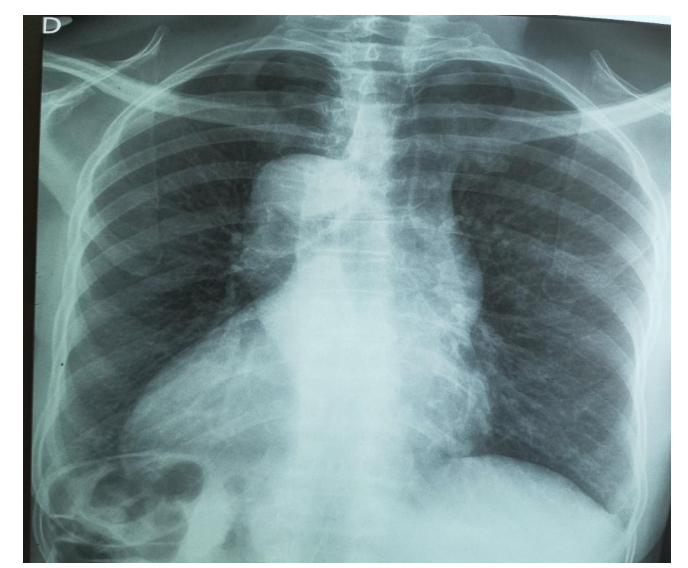

Figure 1 : Frontal Chest $\mathrm{X}$-ray showing dextrocardia making a mirrored heart 


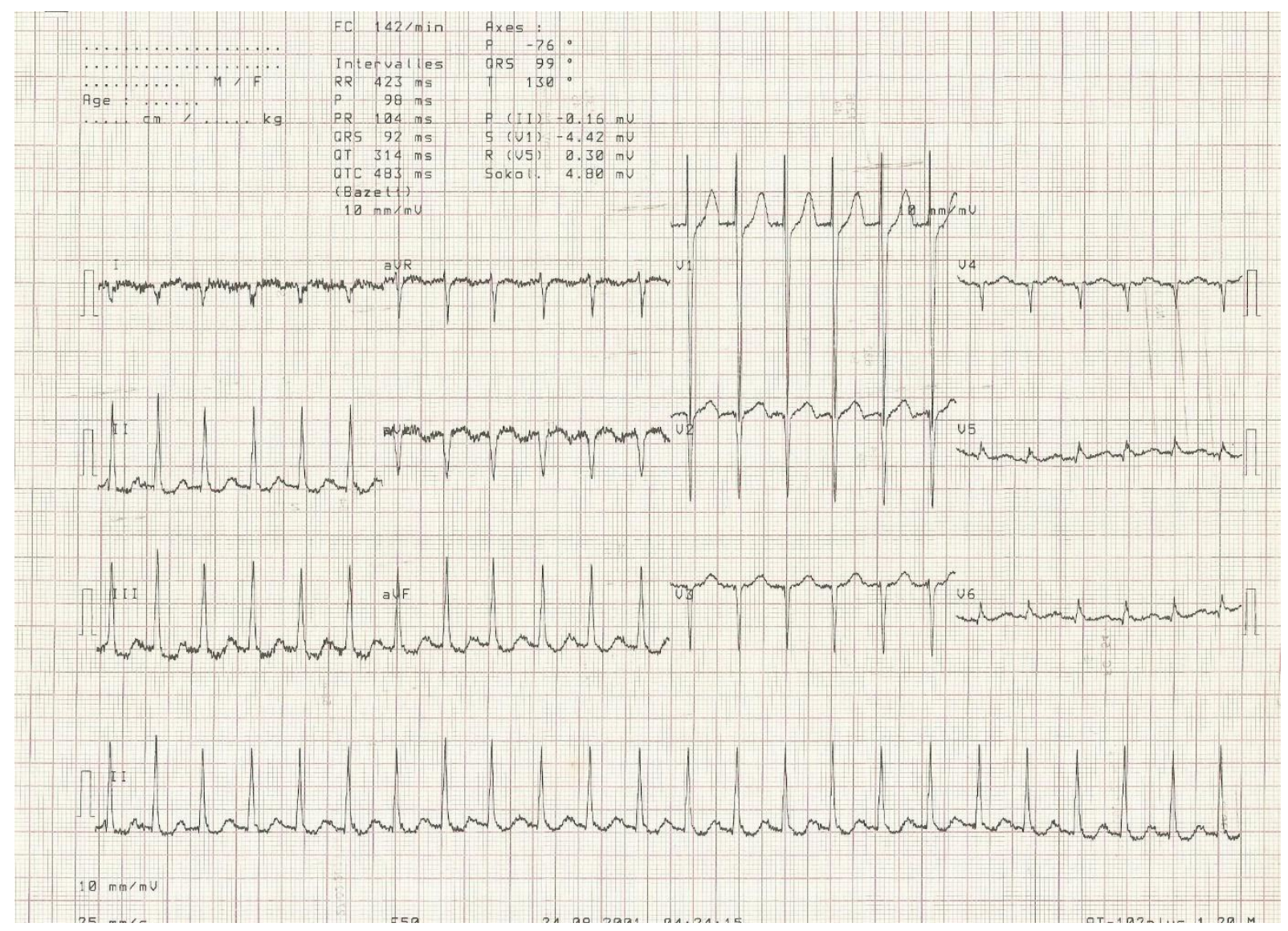

Figure 2 : Electrocardiogram of situs inversus with supraventricular tachycardia

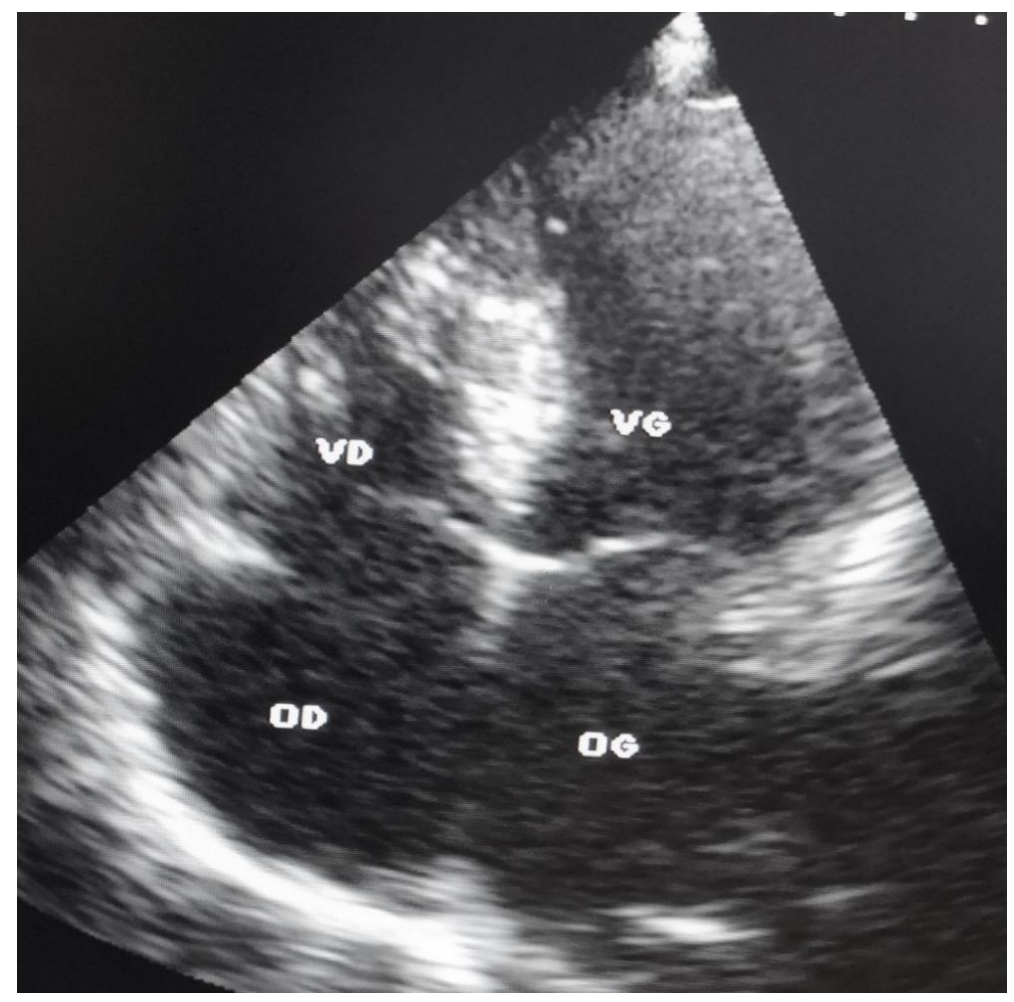

Figure 3 : Apical view with probe mark on right side showing cardiac chambers 


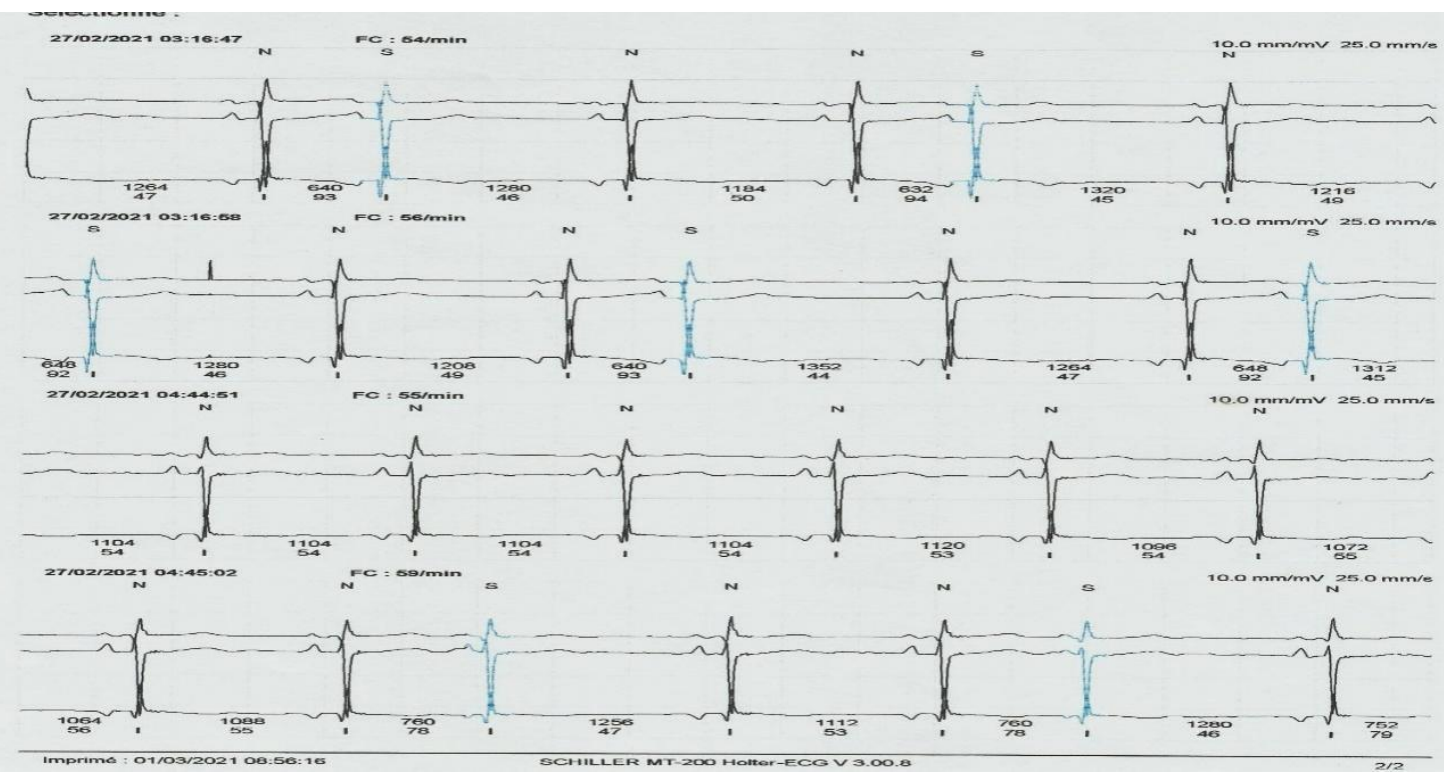

Figure 4 : Sample of long-term electrocardiogram showing recovering of heart rythm

\section{References}

[1] Barre E and Iserin L. Arrhythmias in adults with congenital heart diseases. The Cardiologist's Letter $2012 ; 454-455$ : 22-7.

[2] KHAIRY P. Arrythmias in adults congenital heart disease: what the practicing. Canadian Journal of Cardiology 2019; 35:1698-1707.

[3] ASHUTOSSH N, ABHISHEK N, PRAKASH A and al. Dextrocardia : When Right is Wrong. Journal of Atrial Fibrillation $2020 ; 13: 1-5$.

[4] BELLAVANCE M. Supraventricular tachycardia in Children. Paediatr Child Health $2001 ; 6: 586-9$.

[5] MALDJIAN PD and SARIC M. Approach to Dextrocardia in Adults: Review. AJR Integrative Imaging $2007 ; 188: 39-49$. 